\title{
Methodological Concerns in the Study of Intergenerational Transmission of Criminal Behavior and Children of Incarcerated Parents
}

\author{
Nicolle Parsons-Pollard*
}

\author{
Associate Professor and Criminal Justice Undergraduate Program Coordinator, Virginia State University, P.O. Box \\ 9036, Colson Hall 200C, Virginia State University, VA 23806, USA
}

\begin{abstract}
This study seeks to focus on the methodological concerns found in intergenerational transmission of criminal behavior studies of children of incarcerated parents. In reviewing the literature it is evident that parental incarceration has a significant impact on children but unfortunately many of the studies suffer from methodological concerns that limit the generalizability of the findings and the ability to extend the origins of the antisocial behavior across generations. The concerns include 1) the lack of reliable data available 2) small sample sizes and lack of control groups 3) lack of variation in reporters of data 4) very little information about subjects before incarceration 5) the need for data related to high risk urban populations 6) the use of retrospective data, and 7) few studies the meet the criteria outlined by Thornberry.
\end{abstract}

Keywords: Intergenerational transmission of crime, children of incarcerated parents, life-course, trajectory, and transitions.

\section{INTRODUCTION}

Despite the vast amount of research on intergenerational transmission of criminal behavior, very few of those works focus specifically on incarcerated parents and the life course of possible criminal activity related to their children. Often the discussion of such intergenerational transmission or sometimes referred to as role reversals in the life course is used to describe the idea that "violence begets violence" and victims moving to become offenders or vice versa over time [1]. According to Widom [2], "Researchers and professionals have used the phrases 'cycle of violence' and intergenerational transmission of violence' loosely to refer to assumptions or hypotheses about the consequences of abuse and neglect in relation to a number of different outcomes."

The notion of intergenerational transmission of criminal behavior in regards to children of incarcerated parents is considered to be somewhat intuitive. It is often regarded that children who are exposed to certain subcultures will likely yield to the values of those subcultures. And while several researchers have hypothesized that children of incarcerated parents are at risk for criminal behavior [3-7], there remains very little empirical research on this topic. One more recent study [8] revealed that parental incarceration was linked to increases in antisocial behavior and increased juvenile and adult offending. Unfortunately, this study as with others has some methodological issues that limit the findings.

This article will explore the methodological issues in many studies that attempt to draw conclusions about children of incarcerated parents and their future outcomes. This article will seek to do this by looking at intergenerational transmission of criminal behavior in regards to children of incarcerated parents in the United States and discuss some of the methodological shortcomings presented in the literature. In particular, the article

*Address correspondence to this author at the Virginia State University, P.O. Box 9036, Colson Hall 200C, Virginia State University, VA 23806, USA;

Tel: 804-524-6923; Fax: 804-524-6883; E-mail: nparsons-pollard@vsu.edu will address issues related to children of incarcerated parents, explain what life-course and intergenerational transmission of criminal behavior are and how they have been studied previously, and the recommend methodological criteria for intergenerational studies.

\section{CHILDREN OF INCARCERATED PARENTS}

According to the Bureau of Justice Statistics [9] approximately $1,518,535$ people are in prison. Of those incarcerated it is estimated that 809,800 are parents and the number of women imprisoned has grown at a faster rate than those for men. More than 7 million children in the United States have parents under some type of correctional authority (i.e. prison, jail, probation etc.) [10]. The impact of parental imprisonment also impacts African Americans disproportionately. African Americans are seven and a half times more likely than Caucasian children to have a parent in prison and Hispanic children are more than two and a half times more likely than Caucasians [9]. These numbers are at best estimates because prisoners are not required to release information about their offspring and the counts that are available are gathered through voluntary self-reports from inmates [11].

Incarceration has a variety of collateral consequences, which impact family, friends, and the community. The life course perspective is described as "a sequence of socially defined events and roles that the individual enacts over time" [12]. Exploring the plight of children of incarcerated parents is important because it impacts the trajectory of their lives, which can lead to delinquency and possible adult offending [13]

While there are generally a multitude of problems before incarceration including poverty, family dysfunction, substance abuse, and criminal behavior [14], a host of stressors are related to the incarceration of a parent. Most importantly, a parent is taken out of the home and the parent-child separation can contribute to adolescent antisocial behavior due to lack of contact. According to Hairston, Rollin, and Jo [15] a survey of State prisoners across the country revealed that $54 \%$ with minor children had not seen them since they were incarcerated. Most 
children will correspond with the incarcerated parent through mail or telephone [16]. Parent-child visits are impacted by two factors 1) the caregiver must initiate the visit and may not be willing to do so and 2) the visit can be costly. Sixty percent of parents in State prisons and $85 \%$ of those in Federal prisons are housed more than 100 miles from their last residence [16].

In addition, there are some comparisons of children of incarcerated parents to children who experience the loss of a parent through death, divorce or child welfare circumstances. When a child is separated from a parent, regardless of the circumstances, there is a loss that can generate stress, sadness, fear, loneness and a host of other emotions. According to Lowenstein [17], $40 \%$ of children with incarcerated parents experienced emotional and health problems, which included frequent nightmares and fear of darkness that denote a fear of isolation from others. While the death of a parent is permanent, studies have shown that children of incarcerated parents suffer what is termed as an "ambiguous loss." Ambiguous loss theory is "a state in which family members are uncertain in their perception about who is in or out of the family and who is performing what roles and tasks within the family system [18]." Children who suffer such losses exhibit symptoms of posttraumatic stress syndrome $[19,20]$. The extent to which the child is impacted by the parent's incarceration is largely related to the resilience, quality of the parent-child relationship and other protective factors [21].

Lastly, there are stressors on caregivers of the children as well. When a parent is incarcerated the child is likely to live with a family member or enter the foster care system. When a father is incarcerated the child normally remains with their primary caregiver, which is generally the mother [16]. On the contrary, when a mother is incarcerated the father is less likely to care for the child (25\%) but they are more likely to live with a grandmother $(51 \%)$, another relative $(20 \%)$, a family friend $(4 \%)$, or foster care (11\%) [16].

Relatives caring for children of incarcerated parents generally suffer from the added financial responsibilities, lack of knowledge about social services and educational resources, childcare concerns, and limited healthcare services [22]. They also are less likely to seek public assistance because they fear the child may be removed from the home or the idea of being scrutinized by a public agency is too much to bear [23]. According to Newby [23], when a child is placed with a family caregiver it often results in "financial hardship, disruption in family patterns and roles, family involvement with the criminal justice system, child's behavioral issues, and the challenges of finding resources." While there is little research on the quality of the care children receive from these caregivers, one study did indicate that African American grandmothers, in particular, reported rewarding benefits of raising their grandchild while the parent was incarcerated. The rewards included having a second chance to raise a child properly, preserving family legacies through the grandchildren, and enjoying the love and companionship of the relationship [24]. One common area of focus found in the research related to caregivers of children with incarcerated parents was the lack of resources and needs. As indicated by Newberry [23], caregivers generally need community support, emotional support through counseling services, information about resources available in their community, and opportunities for respite care.

\section{LIFE-COURSE AND INTERGENERATIONAL TRANSMISSION OF CRIMINAL BEHAVIOR}

In order to explore the impact of parental incarceration on future criminality of their children, life-course and intergenerational transmission of criminal behavior will be discussed. According to Elder, "Each generation is bound to fateful decisions and events in the other's life-course" [25]. Simply put events in one's life whether catastrophic or auspicious have an impact on other generations. Life-course is defined as "pathways through the age differentiated life span," where age differentiation "is manifested in expectations and options that impinge on decision processes and the course of events that give shape to life stages, transitions, and turning points" $[25,26]$. The two central concepts that are the foundation for life-course are trajectory and transitions. A trajectory is a pathway that occurs over the life span and transitions are life events that are within the trajectories and occur over short periods of time [26]. For example, marriage might be a transition in one's life course and has been shown to diminish criminal activity. Several studies have shown that offenders who marry are more likely to stop offending [27, 28]. Sampson and Laub [29] found that attachment to a spouse had a greater significance than job stability in explaining the desistance in adult crime.

According to Elder the interlocking nature of trajectories and transitions creates turning points or changes in the life course [25]. Adaptation to events impact the trajectory therefore assumptions about the impact of childhood events on adult experiences may be strongly connected but they can be redirected based on the transitions or turning points. The framework for life-course theory has three central themes: 1) concern with the social meanings of age throughout the life course, 2) intergenerational transmission of social patterns, and 3) the effects of macrolevel events (e.g. Great Depression, World War II) and structural location (e.g. class and gender) on individual life histories [26, 25].

According to Thornberry [30] intergenerational studies should have four criteria. First they should utilize prospective data on Generation 2 parent's and Generation 3 child's involvement in deviant behavior. Second, the measures of antisocial behavior should be "as independent as possible and, whenever possible, based on different reporters" [30]. Third, there should be comparable measures of Generation 2 and Generation 3's antisocial behavior that encompass the same ages or developmental stages in life. Fourth, studies should also have prospective data on Generation 2 in order to identify mediating factors that impact continuity or discontinuity.

This critical criterion of intergenerational studies differentiates them from longitudinal studies. Whereas longitudinal studies focus on the concurrent relationship between the parent's antisocial behavior and the child's adolescent behavior, intergenerational studies allow comparisons of Generation 2 and Generation 3 [30]. Secondly, intergenerational studies can estimate the impact of a parent's adolescent antisocial behavior on their child's adolescent behavior [30]. While much of what we know about the children of incarcerated parents is from longitudinal data the move toward stronger intergenerational studies is important to understanding the origins and path of deviant behaviors. 


\section{PREVIOUS RESEARCH}

The previous research in regards to children of incarcerated parents has been relatively consistent. Each study presented shows there are indeed negative impacts on children when their parents are incarcerated and this often leads to future criminality for the child and can extend into their adulthood. Sampson and Laub [29] utilized Gluecks' data originally collected from 1924 to 1935 . The data revealed that there was a significant correlation between the father's criminal behavior and their son's criminality. In the Chicago Youth Development Study [31] longitudinal data of inner city, economically disadvantaged African-American and Latino boys and their caregiver(s) were collected. The results revealed that persistent delinquents were more likely to come from families with deviant backgrounds. "The group involved in serious chronic offending was more likely to have families characterized by multiple problems including disruption, conflict, and lack of parental involvement, sometimes so extreme as to meet the legal requirement of neglect" [31].

Similar results were found in the Pittsburg study. Farrington et al. [32] researched how far criminal relatives can forecast delinquency in boys. This study was largely different from others because in addition to nuclear family data it utilized information about uncles, aunts, grandfathers, and grandmothers. The Pittsburg Youth Study was a prospective longitudinal survey in which three samples of boys totaling 1,517 respondents were asked about offending and other antisocial behavior. The boys were a mix of Caucasian and African American and all attended Pittsburg public schools. The findings showed that the arrest of relatives could predict a boy's delinquency. The data also revealed that the arrest of the father was the best predictor. Farrington et al. [32] also offered six possible explanations for the findings. First, the intergenerational transmission of criminal behavior is just a part of a larger "cycle of deprivation and antisocial behavior." This cycle includes multiple risks such as generational poverty, teen pregnancy, and living in deprived areas. A second explanation deals with "assortative mating." The study found that female offenders were likely to marry or live with other offenders. In many cases the women were less likely to have the skills necessary to provide proper parenting and minimize delinquency risks. The third explanation focuses on the influence of other family members and imitation. Hence, boys model the behaviors they see. Fourth, environmental mechanisms mediate between the parental criminality and juvenile delinquency. Therefore, poor parenting, supervision, and lack of attachment can be the causal link. The fifth explanation focuses on genetic factors. This explanation posits that offenders may have some genetic predisposition that is passed on to their offspring. The sixth explanation centers on the stigma of being in a family of offenders and that bias causes police and courts to respond negatively [32].

The Rochester Youth Development Study [33, 34] also takes an important look at intergenerational transmission of criminal behavior. It is a prospective longitudinal study that began in 1988 and included the initial sample of 1,000 juveniles, their parents and eventually their children - for three generations. The results of the study have shown that there is some evidence of intergenerational transmission but not strong. The data did show that parental antisocial behavior can lead to aggression in their children and this can result in delinquency.
Kim et al. [35] examined gender specific pathways in intergenerational transmission of internalizing and externalizing behaviors. The behaviors where examined over three generations and the results showed that mothers internalizing behavior heavily influenced her offspring regardless of gender. The data also showed that fathers had a larger influence on female children and only a limited influence with male children. Giordano and colleagues [36] utilized the Ohio Life Course Study data, which was first collected in 1982 and had followups in 1995 and 2003. The data consists of interviews with 127 girls and 127 boys who were institutionalized for delinquency. This study also found support for intergenerational transmission of criminal behavior.

\section{METHODOLOGICAL CONCERNS AND RECOMMEN- DATIONS}

There are several methodological issues that are cause for concern when examining intergenerational transmission and children of incarcerated parents. This section of the article will review 7 general concerns and recommendations that have been previously mentioned in the literature [14, 21, 30, 31, 32, 37]. The concerns include 1) the lack of reliable data available 2) small sample sizes and lack of control groups 3) lack of variation in reporters of data 4) very little information about subjects before incarceration 5) the need for data related to high risk urban populations 6) the use of retrospective data, and 7) few studies the meet the criteria outlined by Thornberry.

First, while there is a plethora of information about children of incarcerated parents available just by Googling the topic, very little of the data can be deemed reliable. As noted earlier, there is no requirement that inmates provide information about their offspring and much of what we know about the impact of incarceration on children is provided by practitioners who work with families [21]. Another reason reliable data is scarce is because law enforcement, child welfare, and correctional agencies don't routinely track data about a parent's involvement in the criminal justice system and when they do the systems don't normally share data $[14,32]$. Lastly, according to Farrington et al. [32] urban families are "constantly changing and reconstituting, and it is difficult to determine who are the biological fathers, siblings, grandparent, and so forth." In order to increase the validity of the data collected, agencies that house information on incarcerated individuals should make information available across systems. Providing a cross-systems approach will provide the ability to determine the magnitude of the problem and could assist agencies in the provision of services.

Secondly, most studies about parents of incarcerated children involve relatively small samples. Of the studies reviewed in this article most only had a few hundred subjects in the data sets used to analyze intergenerational transmission. For example, the Sampson and Laub study had 480 subjects and their fathers, the Ohio Life-Course study had 254 boys and girls total, and the Oregon Youth Study had 206 boys and their families $[29,27,35]$. Not only were many of the sample sizes small but they often lacked the use of a control group and randomization. Utilizing larger samples in this type of research will provide greater generalizability for the results and utilizing randomization and control groups will allow for more confidence in the research outcomes. 
Third, in looking at the reporter used in most studies they generally rely on one person and utilize only self-report data. For example, the Pittsburg Youth Study only utilized data captured from the parent [32]. Farrington et al. [32] Acknowledged that this limitation impacted the data collected because the parent may not have been aware of some information that was crucial or may have some bias. This sole source data can provide a distorted view on the patterns produced across generations [38]. Also, utilizing self-report data can always be tricky due to issues of validity. Some studies found that African Americans were likely to underreport certain types of behavior while others found very little difference [39]. It is highly recommended that using multiple reporters for this type of data collection will offer increased confidence in the findings and help to cancel out some bias that may be embedded in responses.

Fourth, there appears to very little data about the children before the parent becomes incarcerated. While there is some evidence that there may be some level of family dysfunction before the arrest, there is generally little access to that information $[14,40]$. This battle of temporal order complicates determining if the parental incarceration was the impetus for antisocial behavior or if the behavior was evident before the incarceration [40]. This is another instance in which utilizing cross-systems data (police, child welfare, school etc.) can be helpful in painting the picture of what the home life of the child looked like before the incarceration of the parent. Providing this before snapshot can help researchers tease out what impacts are directly related to the incarceration and which were present before.

Fifth, there is a need for data collection in higher risk urban areas. It has been well established that environments and certainly disorganized environments can serve as risk factors. For example, impoverished communities often act as a barrier for families and residents find it difficult to break out of the cycle of poverty, which can impact their overall quality of life [41]. The Chicago Youth Development Study was one such study that focused on higher risk populations by concentrating on non-white boys living in an economically disadvantaged area in Chicago. Collecting data from higher risk populations will help to determine if there are differences in outcomes in comparison to those that may not be in urban areas or from more troubled backgrounds. Assessing the impact of environment can further assist in teasing out true intergenerational impacts.

Sixth, many of the earlier studies utilize retrospective data collection. Retrospective recollection can be problematic because it relies on respondents to recall information accurately [42]. The problems associated with such types of data have been widely published but it is still often utilized due to affordability, convenience, and less restrictive human subjects criteria [43]. Unfortunately, this type of data collection results in making it difficult to trace patterns of transmission appropriately. It is recommended that when possible prospective data should be utilized. Prospective data collection allows researchers to design the study and follow subjects forward in time rather than asking subjects to recall information. This type of research provides greater opportunities for randomization and the use of control groups as well.

Seventh, few studies meet the criteria Thornberry recommends. As mentioned previously, this criterion is based on four core elements that are necessary to clarify intergenerational transmission patterns. The elements include prospective data on the Generation 2 parent's and Generation 3 child's involvement in delinquency, the measures of antisocial behavior should be independent and from multiple reporters, there should be comparable measures of Generation 2 and Generation 3's antisocial behavior at similar ages or developmental stages in life, and there should be prospective data on Generation 2 to identify mediating factors [30]. When consideration is given to these four elements, the findings of intergenerational studies become stronger. Collecting prospective data and data across the life-course helps researchers when attempting to measure any behavior of interest and not just criminality.

\section{CONCLUSION}

The basic premise of this article is to focus on the methodological concerns found in intergenerational transmission of criminal behavior studies of children of incarcerated parents. Some might say that what we know about the impact of parental incarceration on children is largely anecdotal. While this may or may not be the case, it is more important that researchers focus on the methods that are employed when attempting to study any type of intergenerational transmission of behavior. According to Thornberry, the apple doesn't fall far from the tree and parents and children are alike in regard to antisocial behavior [30]. Addressing the methodological concerns presented will help researchers and practitioners further understand influences on a child's behavior, mediating factors, the impact of parenting styles and behaviors, and how to provide preventative services. It is important to know how children are impacted when their parent or parents are incarcerated and if that impact leads to delinquency. The data shows that there are some tremendous impacts psychologically, socially, and behaviorally. But until studies utilize appropriate methods it is difficult to empirically link these impacts to future criminality.

All studies have limitations but some are possible to manage. This article seeks to provide a path for more methodologically sound studies when exploring the life-course of children with incarcerated parents. Common sense tells us there are severe impacts on children that face this type of loss but the question is what do the data show?

\section{ABOUT THE AUTHOR}

Nicolle Parsons-Pollard is an Associate Professor in the criminal justice program at Virginia State University. She is a graduate of Virginia Commonwealth University (VCU) and has a Ph.D. in Public Policy and Administration. Currently, her research includes disproportionate minority contact (DMC), juvenile delinquency, truancy, and program evaluation. She is also a co-organizer of the only annual conference in Virginia on DMC.

\section{ACKNOWLEDGEMENT}

None declared.

\section{CONFLICT OF INTEREST:}

None declared.

\section{REFERENCES}

[1] Moriarty L, Parsons-Pollard N. Role reversals in the life-course: a systematic review. Victims Offenders 2008; 3(4): 331-45. 
[2] Widom C. The cycle of violence. Science 1989; 244: 160-7.

[3] Dalley LP. Policy implications relating inmate mothers and their children: will the past be prologue. Prison J 2002; 82: 234-68.

[4] Eddy JM, Reid JB. The antisocial behavior of the adolescent children of incarcerated parents: a developmental perspective. Paper presented at the From Prison to Home Conference: Washington, DC 2002.

[5] Hagan J, Dinovitzer R. Collateral consequences of imprisonment for children, communities, and prisoners. In: Tonry M, Petersilia J, Eds. Prisons, University of Chicago Press 1999; pp. 121-62.

[6] Johnston D. Effects of parental incarceration. In: Gabel K, Johnston D, Eds. Children of incarcerated parents. Lexington Books 1995; pp. 5988.

[7] Travis J, Cincotta EM, Solomon, AL. Families left behind: the hidden costs of incarceration and reentry. Washington, DC: Urban Institute 2003.

[8] Murray J, Farrington DP. Parental imprisonment: effects on boys' antisocial behavior and delinquency through the life course. J Child Psychol Psychiatr 2005; 46: 1269-78.

[9] Glaze EL, Maruschak LM, US Department of Justice; Bureau of Justice Statistics. Parents in prison and their minor children. Rockville, MD: NCJ Publication No. NCJ222984, 2008.

[10] Mumola CJ. Parents under correctional supervision; Past estimates, new measures. As Cited in Paternal Incarceration and Adversity in Young Adulthood, Roettger M, Corrections Today, December 2009.

[11] Nesmith A, Ruhland, E. Children of incarcerated parents: Challenges and resiliency, in their own words. Child Youth Serv Rev 2008; 30: 1119-30.

[12] Giele J Z, Elder GH. Methods of life course research: qualitative and quantitative approaches. Thousand Oaks, CA: Sage 1998; p. 22.

[13] Murray J, Farrington DP. Parental imprisonment: Effects on boys' antisocial behavior and delinquency through the life course. J Child Psychol Psychiatr 2005; 46: 1269-78.

[14] Phillips SD, Bloom B. In whose best interest? The impact of changing public policy on relatives caring for children with incarcerated parents. Child Welfare 1998; 77: 531-41.

[15] Hairston CF, Rollin J, Jo H. Family connections during imprisonment and prisoners' community reentry. Research brief: Children, families, and the criminal justice system. 2004, [Retrieved $2011 \mathrm{Feb} 6$ ] Available from: http://www.uic.edu/jaddams/college/research_public_service/files /familyconnections.pdf

[16] Mumola, CJ. Incarcerated parents and their children. Bureau of Justice Statistics Special Report 2000, Aug [Article NCJ 182335 Retrieved 2011 Feb 5]. Available from: http://bjs.ojp.usdoj.gov/index.cfm?ty=p bdetail\&iid $=981$

[17] Lowenstein A. Temporary single parenthood - The case of prisoners' families. Family Relat 1986; 35: 79-85.

[18] Boss P, Greenberg J. Family boundary ambiguity: A new variable in family stress theory. Family Process 1984; 23: 535-46.

[19] McCloskey LA, Walker M. Posttraumatic stress in children exposed to family violence and single-event trauma. Journal of the American Academy of Child and Adolescent Psychiatry 2000; 39: 108-15.

[20] Bocknek EL, Sanderson J, Britner PA. Ambiguous loss and posttraumatic stress in school-age children of prisoners. J Child Fam Stud 2009; 18:323-333.

[21] Newby, G. After incarceration: adolescent-parent reunification. Prevent Res 2006; 13(2): 18-20.

[22] Harris MS, Skyles A. Kinship care for African American children: disproportionate and disadvantageous. J Fam Issues 2008; 29(8): 10131030.
[23] Newby G. Addressing the needs of those caring for adolescent children of incarcerated parents. Prevent Res 2008; 15: 6-9.

[24] Hanlon TE, Carswell SB, Rose M. Research on the caretaking of children of incarcerated parents: Findings and their service deliver implications. Child Youth Serv Rev 2007; 29: 348-62.

[25] Elder GH, Jr. Perspectives on the life course. In: Elder G H, Jr. Ed. Life course dynamics, Cornell University Press 1985; pp. 23-49.

[26] Sampson RJ, Laub JH. Crime and deviance in the life course. Annu Rev Sociol 1992; 18: 63-84.

[27] Giordano PC, Cernkovich, SA, Rudolph JL. Gender, crime, and desistance: Toward a theory of cognitive transformation. Am J Sociol 2002; 107: 990-1064.

[28] Warr M. Life-course transitions and desistance from crime. Criminology 1998; 36: 183-216.

[29] Sampson RJ, Laub JH. Turning points in the life course: why change matters to the study of crime. Criminology 1993; 31 (3): 301-25.

[30] Thornberry TP. The apple doesn't fall far from the tree (or does it?): Intergenerational patterns of antisocial behavior. Criminology 2009; 47(2): 297-325.

[31] Gorman- Smith D, Tolan P, Loeber R, Henry D. Relation of family problems to patterns of delinquent involvement among urban youth. $\mathrm{J}$ Abnorm Child Psychol 1998; 26(5): 319-33.

[32] Farrington D, Joliffe D, Loeber R, Stouthamer-Loeber M, Kalb L. The concentration of offenders in families, and family criminality in the prediction of boy's delinquency. J Adolesc 2001; 24: 579-96.

[33] Thornberry T. Explaining multiple patterns of offending across the life course and across generations. The ANNALS of the American Academy of Political and Social Science 2005; 602(1): 156-95.

[34] Thornberry T, Freeman-Gallant A, Lovegrove P. Intergenerational linkages in antisocial behavior. Crim Behav Ment Health 2009; 19: 8093.

[35] Kim H, Capaldi D, Pears K, Kerr D, Owen L. Intergenerational transmission of internalising and externalizing behavior across three generations: Gender-specific pathways. Crim Behav Ment Health 2009; 19: 125-41.

[36] Giordano P. Legacies of crime: A follow-up of the children of highly delinquent girls and boys. Cambridge: University Press 2010.

[37] MacEwen KE. Refining the intergenerational transmission hypothesis. J Interpers Violence 1994; 9: 350-65.

[38] Thornberry T, Freeman-Gallant A, Lizotte A, Krohn M, Smith C. Linked lives: the intergenerational transmission of antisocial behavior. J Abnorm Child Psychol 2003; 31(2): 171-84.

[39] Hawkins DF, Laub JH, Lauritsen JL, Cothern L. Race, ethnicity, and serious and violent juvenile offending. Office of juvenile justice and delinquency predention 2000; Washington D.C. [Retrieved 2011 Jan 28]. Available from $:$ http://www.ncjrs.gov/pdffiles $1 /$ ojjdp/181202.pdf

[40] Huebner B M, Gustafson R. The effect of maternal incarceration on adult offspring involvement in the criminal justice. J Crim Just 2007; 35: 283-96.

[41] Miller K M. Risk and resilience amoung african american children of incarcerated parents. African Am Behav Soc Environ 2007; 15: 25-37.

[42] Widom CS, Shepard RL. Accuracy of adult recollections of childhood victimization: Part I. Childhood physical abuse. Psychol Assess 1994; 8: 412-21.

[43] Wareham J, Paquette Boots D, Chavez, J M. A test of social learning and intergenerational transmission among batters. J Crim Just 2009; 37: $163-73$ 